\title{
Influence of male size and mating history on sperm content of ejaculates of the blue crab Callinectes sapidus
}

\author{
Matthew S. Kendall ${ }^{1, *}$, Donna L. Wolcott ${ }^{2}$, Thomas G. Wolcott ${ }^{2}$, Anson H. Hines ${ }^{3}$ \\ ${ }^{1}$ NOAA/NOS Center for Coastal Monitoring and Assessment, 1305 East-West Highway, Silver Spring, Maryland 20910, USA \\ ${ }^{2}$ North Carolina State University, Department of Marine, Earth and Atmospheric Sciences, PO Box 8208, Raleigh, \\ North Carolina 27695-8208, USA \\ ${ }^{3}$ Smithsonian Environmental Research Center, PO Box 28, Edgewater, Maryland 21037, USA
}

\begin{abstract}
Laboratory experiments were used to determine the influence of male Callinectes sapidus (Rathburn) size (larger vs smaller than the size limit of the hard crab fishery in Chesapeake Bay, which is $127 \mathrm{~mm}$ carapace width) and mating history (recently mated males with depleted seminal stores vs those with fully recovered resources) on number of sperm transferred to females. Females mated by males with fully recovered seminal resources received significantly more sperm than those mated with males that had mated once previously, regardless of male size. No significant difference was found between the number of sperm delivered by small and large males with similar mating history. The sperm content of ejaculates from these laboratory experiments was compared to sperm received by females collected in the field. Only $11 \%$ of field-collected females received an amount of sperm as large as that delivered by the fully recovered males in our laboratory experiments. Of the field collected females, $77 \%$ received much less sperm, similar to or below the number delivered by depleted males in our laboratory experiments.
\end{abstract}

KEY WORDS: Blue crab $\cdot$ Reproduction $\cdot$ Male size $\cdot$ Mating history $\cdot$ Ejaculate contents

\section{INTRODUCTION}

Recently, much research has been focused on the possibility of sperm limitation in commercially exploited populations of crustaceans (Paul 1984, Waddy \& Aiken 1986, Wenner 1989, Prager et al. 1990, Smith \& Jamieson 1991, Sainte-Marie \& Hazel 1992, Hankin et al. 1997, Paul \& Paul 1997). This is not surprising since such fisheries are often regulated by minimum size limits that result in preferential removal of many of the largest males. Females in these populations may mate with males that are smaller and presumably produce less sperm than larger males. These smaller males are also potentially mating with higher frequency than they

*E-mail: matt.kendall@noaa.gov would under normal (non-fished) conditions, since there are fewer males per receptive female. Small males that mate frequently may not be able to completely replenish their seminal resources (sperm and/or accessory fluid) between mating with successive females. Females mating with such males may receive less sperm and seminal fluid than if they had mated with a larger, fully recovered male, which may reduce the number of eggs they are able to fertilize.

In addition to the influence of commercial fisheries on population structure, aspects of the reproductive biology of many crustacean species may make them particularly susceptible to sperm limitation. For example, females of many commercially exploited crustacean species produce many eggs and therefore require many sperm, have limited temporal opportunity to receive sperm (usually based on molt stage), and often 
must store and maintain viable sperm for some time before using them to fertilize eggs. All of these life history traits suggest that the number of sperm and amount of seminal fluid received by females can have a dramatic influence on fertilization success.

Despite a wealth of studies on the limits and mechanisms of crustacean reproduction (Gray \& Powell 1964, Waddy \& Aiken 1990, Paul \& Paul 1992, Stevens et al. 1993, Sainte-Marie \& Lovrich 1994, Prager 1996, Sainte-Marie \& Sainte-Marie 1999), few have conclusively demonstrated sperm limitation. This is attributable both to the large number of factors that must be identified to determine if sperm limitation is occurring and to the difficulty of determining the underlying causes. Such factors include number of eggs produced, number of sperm required to fertilize each egg, number of sperm delivered by males of different sizes and conditions, longevity of sperm once transmitted to the female, receptivity/ability of females to mate/remate, and the amount and quality of sperm received by females in the field.

Recent research addressing these factors indicates that 2 of the biggest influences on ejaculate size and quality are male size and mating history. For example, male size and mate order affects sperm quantity and can thereby modulate clutch weight in spiny lobsters. Female Panulirus argus and Jasus edwardsii mated with small males produce small egg clutches (MacDiarmid \& Butler 1999). Similarly, small male king crabs Paralithodes camtschaticus experience reduced reproductive success after 7 consecutive matings, whereas large males experience no such reduction until 9 consecutive matings (Powell et al. 1974). Large male blue crabs Callinectes sapidus that have recently mated have only a fraction of the vas deferens weight (sperm plus accessory seminal fluid) of those that have not (Kendall et al. 2001).

Research investigating the possibility of sperm limitation in blue crabs has gained momentum in the wake of recently discovered circumstantial evidence. Fishery mortality is higher in males than in females in some areas of Chesapeake Bay (Casey et al. 1990). In addition, average male size has shown a steady decline in the upper Chesapeake Bay over the past few decades, while female size has not (Abbe \& Stagg 1996). Furthermore, many males in an upper Bay population have a vas deferens weight much lower than that expected for a male with fully recovered sperm resources (Kendall et al. 2001). The combination of these factors brings into question the ability of males to adequately inseminate all females in this population (Hines et al. 2001).

While this preliminary evidence suggests that sperm limitation could be occurring, additional information is required to demonstrate it conclusively (Hines et al. 2001). Recent research has provided information on the amount of sperm males have available in the field (Kendall et al. 2001), but how much of that available sperm is delivered by males of different sizes and mating histories is unknown. Females typically receive sperm for their entire lifetime from 1 male during a single mating opportunity and then must store this sperm for many months prior to use (Millikin \& Williams 1980). What, therefore, is the longevity of sperm in storage? How many sperm are used to fertilize each egg? Will seminal resources become exhausted for a given female prior to completion of egg production?

We combined laboratory experiments and field observations to address the first of these issues. Our objectives in this study were to (1) determine the influence of male size (relative to the fishery size limit) and mating history on the number of sperm transferred to females in the laboratory, and (2) evaluate the amount of sperm received by females in the field relative to females in our laboratory experiments.

\section{MATERIALS AND METHODS}

All experiments and collections were conducted at the Smithsonian Environmental Research Center located on the Rhode River, a subestuary of Chesapeake Bay in Maryland, USA $\left(38^{\circ} 51^{\prime} \mathrm{N}, 76^{\circ} 32^{\prime} \mathrm{W}\right)$. The salinity range in the Rhode River is 5 to $15 \mathrm{PSU}$ from spring to fall; the temperature range is 0 to $29^{\circ} \mathrm{C}$ from winter to summer.

Laboratory experiments: influence of male size and mating history on amount of sperm in ejaculates. We compared ejaculate contents for female Callinectes sapidus mated with small or large males with 2 mating histories: fully recovered or recently mated. Males were collected from the Rhode River by crab pot and separated into large (>140 mm carapace width, CW) and small (115 to $127 \mathrm{~mm} \mathrm{CW)} \mathrm{size} \mathrm{classes.} \mathrm{Size} \mathrm{class}$ limits were selected to ensure that all individuals in the small size class were mature (males reach maturity at $\sim 110$ mm CW: van Engel 1990), but below the current harvestable size limit for the blue crab fishery in Maryland. The large size class limit was selected to provide a contrast group well above the legal limit of the fishery. Only intact, intermolt (hard-shelled; Molt Stage C) males were used in these experiments.

Males were held in large submerged pens in the field for a period of $20 \mathrm{~d}$. Previous research indicates that this is sufficient time for males to completely replenish any seminal resources that may have been spent prior to collection (Kendall et al. 2001). An amount of food was provided that is consistent with estimated feeding rates for crabs of this size (Nye 1989). At the end of the $20 \mathrm{~d}$ holding period crabs were in good condition (active and intact). 
Males were then allowed to mate normally with receptive females obtained from a commercial provider near the study site. Females were all pubertal pre-molt stage, although their size was variable. Females were assigned to males haphazardly. Once mating had been completed and the female was observed to be in post copulatory mate guarding position (held below the male by his first pair of walking legs: Hartnoll 1969), she was removed for analysis and a second receptive female was provided to the male. Males usually mated with this second female within 2 to $4 \mathrm{~d}$, depending on the female's molt cycle. Once mating had been completed with the second female (postcopulatory mate-guarding position was attained), she was removed for analysis.

This yielded 4 groups of females: those mated with fully recovered males and those mated with males that had recently been mating, for each of 2 size classes of males respectively. Spermathecae of these inseminated females were removed, weighed, and preserved in $70 \%$ ETOH for sperm count analysis.

Field data: amount of sperm received by females in the Rhode River. Female crabs were sampled monthly (June to October) in 1996 and 1997 by otter trawl from a variety of habitats and depths throughout the Rhode River to determine the amount of sperm they received. Trawls were conducted 3 times $\mathrm{mo}^{-1}$ at each of 4 sites: a shallow ( $2 \mathrm{~m}$ deep) mud-bottom site at the head of the sub-estuary, a sand bottom site ( 2 m deep) at the mouth of the sub-estuary, a $\sim 4$ m deep mud bottom site at the mouth, and a deep $(\sim 4 \mathrm{~m})$ site out in Chesapeake Bay off the mouth of the Rhode River. While no sampling strategy is perfectly representative of a population, ours captured a suitable cross-section of blue crabs in the Rhode River for this study, since it incorporated multiple habitat types used by crabs at locations from the head of the sub-estuary to where it opens into the Chesapeake Bay (Hines et al. 1987). Data recorded for each mature female included carapace width, molt stage, spermathecal weight, and sperm count. Since females do not extrude and fertilize eggs in the upper Chesapeake Bay, none of the females in our field samples would have expended any sperm in production of broods.

This sampling strategy and experimental design enabled us to (1) evaluate the amount of sperm received by females representative of the Rhode River sub-estuary, (2) determine if the amount of sperm received by females changed over the course of the reproductive season, and (3) compare the amount of sperm received by females in the field to those in our laboratory experiments.

Sperm count analysis. Spermathecal weight and the total number of sperm were determined for each female from the field collections and laboratory experiments.
Number of sperm was determined by direct counts of sub-sampled spermathecal contents. First, the entire contents of the spermathecae were homogenized in a minimal volume of 30 PSU artificial seawater. Samples were then passed through a $35 \mu \mathrm{m}$ filter to separate large bits of ruptured spermatophores from sperm cells. Both the filter and the filtrate were examined to ensure that all spermatophores were ruptured and all sperm were passing through the filter. Samples were then stained using 1 drop of $1 \%$ gentian violet per $10 \mathrm{ml}$ sample volume. Ten $\mu$ of the diluted sample were placed on a spermacytometer and allowed to settle for 5 min. Sperm were counted under phase contrast using oil immersion at $1000 \times$ magnification. The total number of sperm in each sample was then extrapolated from the volume counted to the total dilution volume.

Statistical analyses. All sperm-count data were logtransformed during tests of significance to meet assumptions of normality and homogeneity of variance. Sperm counts and spermathecal weights for females in different mating treatments in the laboratory and sperm counts among months for field samples were compared using the Tukey-Kramer multiple comparison test. An ANOVA and simple linear regression were used to determine if there was a relationship between female body size and the amount of sperm they received in the field samples.

\section{RESULTS}

\section{Laboratory experiments: influence of male size and mating history on amount of sperm in ejaculates}

Females mated with large males that had completely recovered their sperm resources received significantly more sperm than those mated with large males that

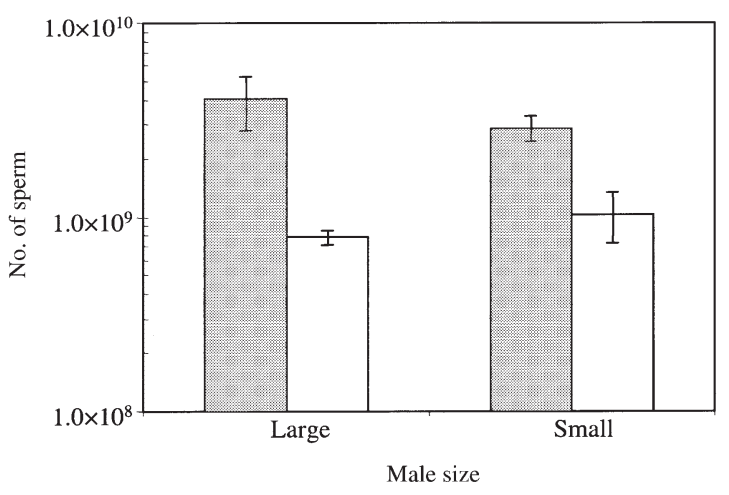

Fig. 1. Callinectes sapidus. Sperm counts in ejaculate delivered by small (115 to $127 \mathrm{~mm}$ carapace width, CW) and large (>140 mm CW) males with fully recovered (shaded bars) and depleted (open bars) seminal resources respectively 
had mated once previously $\left(4.02 \times 10^{9}\right.$ vs $7.9 \times 10^{8}$; Student's $t=3.49, \mathrm{p}<0.007$; Fig. 1). Similarly, females mated with small males that had completely recovered their sperm resources received significantly more sperm than those mated with small males that had mated once previously $\left(2.86 \times 10^{9}\right.$ vs $1.03 \times 10^{9} ; t=3.86$, $\mathrm{p}<0.003$; Fig. 1). Interestingly, no significant difference was found between the number of sperm delivered by small $(\mathrm{p}<0.9)$ and large $(\mathrm{p}<0.9)$ males with the same mating history (Fig. 1).

\section{Field data: amount of sperm received by females in the Rhode River}

We found no significant differences in the number of sperm received by females collected in different months and also no significant relationship between female size and the amount of sperm they received. We also compared how much sperm females in the field received relative to the females in our laboratory experiments. Since the only differences we found in the amount of sperm received by females in our laboratory experiments were due to mating history of males, for comparison with field-caught females we pooled the laboratory samples into 2 groups: mated with 'fully recovered' or with 'depleted' males. In the laboratory experiments, females that mated with 'fully recovered' males received $3.35 \times 10^{9}$ sperm $( \pm 5.69$ $\times 10^{8} \mathrm{SE}$ ), whereas females that mated with 'depleted' males received $9.31 \times 10^{8}$ sperm $\left( \pm 1.75 \times 10^{8}\right)$.

Only $11 \%$ (5 out of 47 samples) of field-caught females had received an amount of sperm similar to the mean amount delivered by a fully recovered male (Fig. 2). The majority of females, 77\% (36 of 47 samples), received much less sperm, similar to or

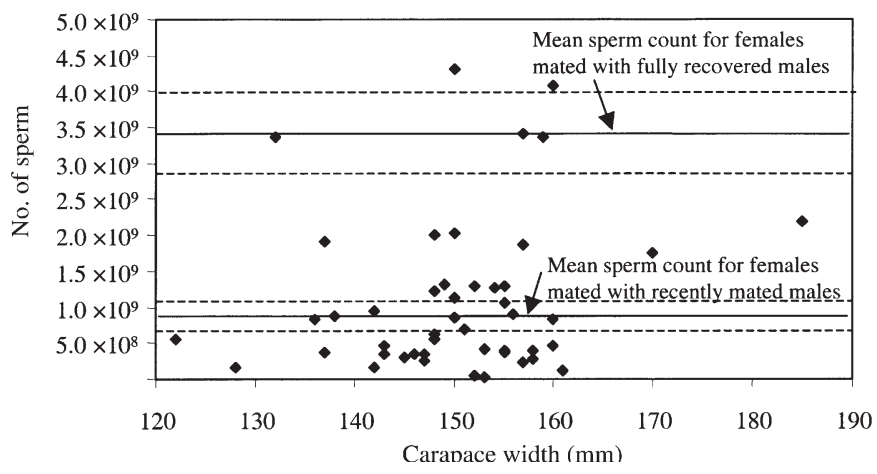

Fig. 2. Callinectes sapidus. Carapace width and sperm counts of ejaculate for mature females sampled from Rhode River $(\mathrm{n}=47)$. Upper and lower sets of solid and dashed lines: mean sperm count and standard error of the mean for females in laboratory experiments receiving sperm from fully recovered and recently mated males respectively below the number delivered by a depleted (previously mating) male. The remaining females $(13 \%$, or 6 out of 47 ) received an intermediate amount of sperm.

\section{DISCUSSION}

Previous research on blue crab mating suggested that the amount of sperm transferred is positively correlated with male size. However, these results were based on the difference between sperm counts in males before versus after mating (Kendall et al. 2001) or inferred from the weight of spermathecal contents, rather than on direct counts. Our results, based on direct counts of sperm transferred to females, indicate that male size did not have a significant effect on the number of sperm received by females, at least in the size classes of males that we tested. Males below the size limit of the fishery were able to deliver just as many sperm as larger males with a similar mating history.

Smaller males that were allowed to completely recover their seminal resources have been shown to have more highly concentrated sperm than small males with intermediate recovery, and even some large males (Kendall et al. 2001). However, while these small males can deliver many sperm, it appears that they have much less accessory seminal fluid to deliver (Kendall et al. 2001). Unfortunately, the seminal fluid component of the spermathecal contents could not be evaluated separately in our experiments due to destructive processing of samples for sperm counting.

The consequences to female reproductive success of receiving less seminal fluid with a given amount of sperm are unclear and need to be investigated. In blue crabs, seminal fluid is known to form a 'sperm plug' that may function to both prevent sperm from leaking out of a female once deposited and to prevent competing males from depositing additional ejaculate (Hartnoll 1969, Hines et al. 2001). In other crustaceans, seminal fluid has also been shown to act as an antibacterial agent (Jayasanker \& Subramoniam 1999) and to provide nourishment for sperm during storage (Subramoniam 1991).

We found mating history to have a significant influence on the number of sperm in ejaculates. However, it is not clear that males would re-mate in the field as quickly as they did during our experimental manipulations. Laboratory experiments indicate that the interval between matings with consecutive partners is 7 to $10 \mathrm{~d}$ due to the demands of post- and pre-copulatory mateguarding (Jivoff 1995). If these laboratory estimates accurately portray the duration of mate-guarding in the field, most males should have time to recover most of their sperm resources between consecutive matings. 
Recent research indicates that, at least for large males, all sperm and seminal fluid is recovered between 9 and $20 \mathrm{~d}$ following mating (Kendall et al. 2001). However, this is inconsistent with our observation that the majority of the females in the population are receiving a much lower quantity of sperm than they would have had they mated with a fully recovered male. Indeed, $77 \%$ of the females in our field collections had received a very low quantity of sperm, similar to or even below the amount delivered by the depleted males in our laboratory experiments. This may be partially explained by the fact that males that have recently mated are competitive dominants for mates relative to males that have no recent mating experience (Kendall \& Wolcott 1999). Males may simply be mating more frequently than the time required for full recovery of their sperm resources (i.e. males may not be waiting the 7 to $10 \mathrm{~d}$ suggested by laboratory experiments). In fact it was recently shown that males will spend less time guarding mates as the male:female ratio declines (Jivoff 1997), which would be expected as a result of the preferential harvesting of males.

Other variables that reduce vas deferens weight for male blue crabs and may affect the amount of sperm transferred to females, but which we did not examine in our experiment, include molt stage and general physical condition (e.g. missing or regenerating limbs) (Kendall et al. 2001). In fact, 20 to $30 \%$ of crabs in the Rhode River basin are either pre- or post-molt (Hines et al. 1987), and 17 to $25 \%$ of crabs are lacking and/or regenerating at least 1 limb (Smith \& Hines 1991). Males in these conditions could also be partially responsible for the large number of females receiving the low number of sperm in our field samples.

We found no relationship between female size and the amount of sperm received. Larger females produce more eggs than smaller females (Prager et al. 1990) and presumably would require more sperm to fertilize them all. To accommodate egg production by larger females and not 'waste' sperm on small females, males of some species such as the spiny lobster vary ejaculate size positively with female size (MacDiarmid \& Butler 1999). Other crustaceans are found to have size-assortative mating, whereby large males mate with the largest females (Powell et al. 1974, Smith \& Jamieson 1991). However, our field collections indicate that larger blue crab females do not receive significantly more sperm than smaller females. The degree to which this may affect the ability of larger females to fertilize their lifetime egg production should be evaluated.

While it was not possible to know the size, mating history, or physical condition of the males mating with the females in our field samples, we have documented that the amount of sperm received by most females in the population is much lower than if they had mated with a fully recovered male. To determine if a reduced number of sperm translates into a lower fertilization rate or reproductive output for females, we must determine the number of sperm expended per egg for fertilization, determine the temporal viability of sperm and what role seminal fluid plays in this, estimate the potential lifetime female egg production, and calculate if sperm resources are expended prior to completion of egg production.

Acknowledgements. We thank Kelly Clark, Jen Gavin, Sharon Handley, Midge Kramer, Laura Nye, Keith Ruffin, Jeff Terwin, and the rest of the Smithsonian Environmental Research Center staff for many hours of field assistance and Wynne Bost for many hours of laboratory work. This research was supported by SERC's Graduate Fellowship Program, SERC's Environmental Sciences Program, Disney's Wildlife Conservation Fund grant to A.H.H. and T.G.W., and NSF grants OCE-9711522 to T.G.W. and D.L.W. and OCE-9711843 to A.H.H.

\section{LITERATURE CITED}

Abbe GR, Stagg C (1996) Trends in blue crab (Callinectes sapidus Rathbun) catches near Calvert Cliffs, Maryland, from 1968 to 1995 and their relationship to the Maryland commercial fishery. J Shellfish Res 15:751-758

Casey JF, Daugherty B, Davis G, Uphoff JH Jr (1990) Blue crab management project. Stock assessment of the blue crab in Chesapeake Bay. Maryland Department of Natural Resources, $\mathrm{p}$ 1-21

Gray GW, Powell GC (1964) Sex ratios and distribution of spawning king crabs in Alitak Bay, Kodiak Island, Alaska (Decapoda Anomura, Lithodidae). Crustaceana 10: 303-309

Hankin DG, Butler TH, Wild PW, Xue QL (1997) Does intense fishing on males impair mating success of female Dungeness crabs? Can J Fish Aquat Sci 54:655-669

Hartnoll RG (1969) Mating in Brachyura. Crustaceana 16: 161-181

Hines AH, Lipcius RN, Haddon AM (1987) Population dynamics and habitat partitioning by size, sex, and molt stage of blue crabs Callinectes sapidus in a subestuary of central Chesapeake Bay. Mar Ecol Prog Ser 36:55-64

Hines AH, Jivoff PR, Bushman PJ, van Montfrans J, Reed SA, Wolcott DL, Wolcott TG (2001) Evidence for sperm limitation in the blue crab, Callinectes sapidus. Bull Mar Sci (in press)

Jayasanker V, Subramoniam T (1999) Antibacterial activity of seminal plasma of the mud crab Scylla serrata (Forskal). J Exp Mar Biol Ecol 236:253-259

Jivoff PR (1995) The role of mate guarding, male size, and male investment on individual reproductive success in the blue crab, Callinectes sapidus. PhD thesis, University of Maryland, College Park

Jivoff PR (1997) The relative roles of predation and sperm competition on the duration of the post-copulatory asociation between the sexes in the blue crab, Callinectes sapidus. Behav Ecol Sociobiol 40:175-185

Kendall MS, Wolcott TG (1999) The influence of male mating history on male-male competition and female choice in mating associations in the blue crab, Callinectes sapidus (Rathbun). J Exp Mar Biol Ecol 239:23-32 
Kendall MS, Wolcott DL, Wolcott TG, Hines AH (2001) Reproductive potential of individual male blue crabs, Callinectes sapidus, in a fished population: depletion and recovery of sperm number and seminal fluid. Can J Fish Aquat Sci 58:1168-1177

MacDiarmid AB, Butler MJ IV (1999) Sperm economy and limitation in spiny lobsters. Behav Ecol Sociobiol 46:14-24

Millikin MR, Williams AB (1980) Synopsis of biological data on the blue crab, Callinectes sapidus Rathbun. NOAA Tech Rep NMFS 1:1-39

Nye L (1989) Variation in feeding behavior of the blue crab, Callinectes sapidus (Rathbun). MS thesis, North Carolina State University, Raleigh

Paul AJ (1984) Mating frequency and viability of stored sperm in the tanner crab, Chionoecetes bairdi (Decapoda, Majidae). J Crustac Biol 4:375-381

Paul AJ, Paul JM (1992) Second clutch viability of Chionoecetes bairdi Rathbun (Decapoda: Majidae) inseminated only at the maturity molt. J Crustac Biol 12:438-441

Paul AJ, Paul JM (1997) Breeding success of large male red king crab Paralithodes camtschaticus with multiparous mates. J Shellfish Res 16:379-381

Powell GC, James KE, Hurd CH (1974) Ability of male king crab, Paralithodes camtschatica, to mate repeatedly. Fish Bull (Wash DC) 72:171-179

Prager MH (1996) A simple model of the blue crab, Callinectes sapidus, spawning migration in Chesapeake Bay. Bull Mar Sci 58:421-428

Prager MH, McConaugha JR, Jones CM, Geer PJ (1990) Fecundity of blue crab, Callinectes sapidus, in Chesapeake Bay: biological, statistical and management considerations. Bull Mar Sci 46:170-179

Sainte-Marie B, Hazel F (1992) Moulting and mating of snow crabs, Chionoecetes opilio (O. Fabricius), in shallow waters of the northwestern Gulf of Saint Lawrence. Can J

Editorial responsibility: Otto Kinne (Editor),

Oldendorf/Luhe, Germany
Fish Aquat Sci 49:1282-1293

Sainte-Marie B, Lovrich GA (1994) Delivery and storage of sperm at first mating of female Chionoecetes opilio (Brachyura: Majidae) in relation to size and morphometric maturity of male parent. J Crustac Biol 14:508-521

Sainte-Marie G, Sainte-Marie B (1999) Reproductive products in the adult snow crab (Chionoecetes opilio). II. Multiple types of sperm cells and of spermatophores in the spermathecae of mated females. Can J Zool 77: 451-462

Smith BD, Jamieson GL (1991) Possible consequences of intensive fishing for males on the mating opportunities of Dungeness crabs. Trans Am Fish Soc 120:650-653

Smith LD, Hines AH (1991) Autotomy in blue crab (Callinectes sapidus Rathbun) populations: geographic, temporal, and ontogenetic variation. Biol Bull 180:416-431

Subramoniam T (1991) Chemical composition of spermatophores in decapod crustaceans. In: Bauer RT, Martin JW (eds) Crustacean sexual biology. Columbia University Press. New York, p 308-321

Stevens BG, Donaldson WE, Haaga JS, Munk JE (1993) Morphometry and maturity of paired tanner crabs, Chionoecetes bairdi, from shallow and deepwater environments. Can J Fish Aquat Sci 50:1504-1516

van Engel WA (1990) Development of the reproductively functional form in the male blue crab, Callinectes sapidus. Bull Mar Sci 46:13-22

Waddy SL, Aiken DE (1986) Multiple fertilization and consecutive spawning in large American lobsters, Homarus americanus. Can J Fish Aquat Sci 43:2291-2294

Waddy SL, Aiken DE (1990) Intermolt insemination, an alternative mating strategy for the American lobster (Homarus americanus). Can J Fish Aquat Sci 47:2402-2406

Wenner EL (1989) Incidence of insemination in female blue crabs, Callinectes sapidus. J Crustac Biol 9:587-594

Submitted: July 2, 2001; Accepted: September 13, 2001

Proofs received from author(s): March 8, 2002 